\title{
CONCEPTUAL BASIS OF THE STATE'S TAX SECURITY MODEL
}

\section{${ }^{1}$ Mariana Vykliuk, ${ }^{2}$ Rostislav Mikhailishin, ${ }^{3}$ Oleksandr Kundytskyj, ${ }^{4}$ Oksana Senyshyn, ${ }^{4}$ Natalia Prokopenko, ${ }^{5}$ Volodymyr Olikhovskyi}

\author{
${ }^{1} \mathrm{PhD}$, European University, Lviv branch, 5 Kushevicha str., Lviv, Ukraine. Email address m_vykluk@ukr.net \\ ${ }^{2} \mathrm{PhD}$, Ivan Franko National University of Lviv, 18 Svobody avenue, Lviv, Ukraine. \\ Email address edean@Inu.edu.ua \\ ${ }^{3}$ Dr., Ivan Franko National University of Lviv, 18 Svobody avenue, Lviv, Ukraine. Email address skund@ukr.net \\ ${ }^{4}$ Dr., professor, Department of Management, Ivan Franko National University of Lviv, 18 Svobody avenue, Lviv, \\ Ukraine. Email address Okssenyshyn@gmail.com \\ ${ }^{4}$ Dr., European University, 16 Vernadsky avenue, Kyiv, Ukraine. Email address prokopenko@gmail.com \\ ${ }^{5}$ Assist. Prof., Lviv Polytechnic National University, 12 Stepan Bandera str., Lviv, Ukraine. Email address \\ volodymyr.y.olikhovskyi@1pnu.ua
}

Received 2905 2020; Accepted 31082020

\begin{abstract}
The purpose of the research is to substantiate the conceptual foundations, methodological and organizational basis of the state's tax security. It is noted that the problem of scientific substantiation of the state's tax security is due to the growing number of threats and risks in the tax sphere in all countries without exception. The morphological analysis of the concept of "the state's tax security" is presented. Made the systematization of the existing scientific approaches to the consideration of the research concept. It is noted that tax security should be considered comprehensively in the context of legal, social and economic aspects of its formation. The existing models of states' tax security are characterized. The author's clarification of the content of the definition of "the state's tax security" is presented. The conceptual basis of the model of the state's tax security is formed.
\end{abstract}

Keywords: state's tax security, state's tax potential, tax system, tax policy, state's conceptual basis of tax security. JEL Codes: F52 E62.

\section{Introduction}

The problems of tax security of states have recently become more and more the subject of general discussions and scientific talks in the international community, discussed at round tables and international conferences. It gained scientific discussion and push in the context of the revival of globalization processes and harmonization of states' tax systems. After all, in this context, the decisive place is given to the state's tax security, in particular: combating tax threats arising from the abuse of rights and responsibilities of taxation entities and the formation of the tax potential of the country, as a prerequisite for the state's effective socio-economic development.

Due to the constant search for ways to grow national wealth, and then its distribution, states need rational taxation mechanisms, which are primarily aimed at harmonizing relations between the state, taxation entities and recipients of social benefits. At the same time, alternatives to taxes, as one of the most effective methods of state revenues formation, have not yet been invented. Therefore, according to representatives of various socio-economic spheres and business structures, the growth of threats and risks in the tax sphere is an inevitable process, both nationally and beyond.

Copyright (C) 2020. Published by Vytautas Magnus University. This is an open access article distributed under the terms of the Creative Commons Attribution Non-Commercial 4.0 (CC BY-NC 4.0) license, which permits unrestricted use, distribution, and reproduction in any medium provided the original author and source are credited. The material cannot be used for commercial purposes. 
This requires constant prevention and regulation by the state through the functioning of a special model of the state's tax security, the economic and legal form, which should ensure the creation of a condition by the state for the interaction of personality's interests, businesses and the state, the introduction of mutual responsibility of the tax process entities, that based on the socioeconomic needs of society. This actualizes the scientific issues of theoretical, methodological and practical understanding of tax security as an undivided part of the state's national security in the context of globalization changes and processes.

Among the basic publications it is worth noting the actual ways that served as the basis of scientific research: conceptual principles of research on the tax security essence as an integral part of the state's national security, features of its formation and markers of support (Ivanov, Y. Berezhna, 2010; Podik, Goncharov, 2017; Knyazeva, Davydova, 2017; Tsvily-Buklanova, 2011; Temoveeva, 2011), practical principles of security providing in the field of taxation through the optimization of the states' taxation system (Bensouda, 2016; Bouvier, 2016; Fouquet, 2013; Freeman, 2003; Mullen, 2016), providing proposals for the management of tax risks and threats to the state, especially those arising from intentional tax evasion (Aleshin, Ovchinnikov, Chelysheva, 2012; Criclivaia, Bruma, 2013; Makutenas, Krikshtonatiene, 2017; Nazarova, Hordopolov, 2019; Rossing, 2013; Wunder, 2009).

Highly appreciating the achievements of scientists, economists and government officials, it should be noted that tax security is a relatively young economic category in academia and public administration, and the formation of conceptual foundations for the development of the studied category is ambiguous and poorly understood. This determines the existence of a scientific problem, which is mostly characterized by episodic coverage of theoretical foundations, imperfect development of conceptual foundations for the formation of the model of the state's tax security, tools and mechanisms for its providing both nationally and internationally scapes.

This poses a number of tasks, the solution of which is possible through their scientific study and practical implementation. In a generalized form, the scientific problem facing us, the purpose and objectives of the study requires a systematic approach, which is clearly shown in Fig. 1.

\begin{tabular}{|c|c|c|c|}
\hline \multicolumn{4}{|c|}{$\begin{array}{l}\text { Problem: episodic coverage of theoretical bases, lack of legal category, imperfection of } \\
\text { the developed conceptual and organizational bases of providing the tax security of the state }\end{array}$} \\
\hline $\begin{array}{l}\text { The object of the } \\
\text { research is the tax } \\
\text { security of the state and } \\
\text { the main aspects of its } \\
\text { providing }\end{array}$ & $\begin{array}{r}\text { Purpose: theoretical su } \\
\text { development of scienti } \\
\text { recommendations for provi } \\
\text { of the sta }\end{array}$ & $\begin{array}{l}\text { tiation and } \\
\text { d practical } \\
\text { the tax security }\end{array}$ & $\begin{array}{l}\text { The subject of the research } \\
\text { are theoretical and } \\
\text { methodological, scientific } \\
\text { and practical principles of } \\
\text { the tax security of the state }\end{array}$ \\
\hline \multicolumn{4}{|c|}{ TASK } \\
\hline \multicolumn{2}{|c|}{ THEORETICAL BLOCK } & \multicolumn{2}{|c|}{ ORGANIZATIONAL BLOCK } \\
\hline \multicolumn{2}{|c|}{$\begin{array}{l}\text { - research of scientific thought on understanding the } \\
\text { definition; } \\
\text { - clarification of the concept of "tax security" and their } \\
\text { place in the system of financial and national security; } \\
\text { - research of forms and spheres of tax security. }\end{array}$} & \multicolumn{2}{|c|}{$\begin{array}{l}\text { - definition of conceptual bases of a model } \\
\text { formation of tax safety of the state; } \\
\text { - formation of mechanisms to ensure the state's } \\
\text { tax security on a national and international } \\
\text { scale. }\end{array}$} \\
\hline
\end{tabular}

Fig. 1. Block diagram of the study of the conceptual foundations of the state's tax security

\section{Result analysis and discussion}

The vast majority of scientific papers on the study of tax security is sporadic, which consider it only in the context of the state's national security, as a resource base of society fuctioning, a component of the state's financial security, its regions or administrative units, or as a special tax policy 
for economic and legal relations between tax administrations and the taxpayer. It is repeatedly observed, generalization of tax security through the prism of fiscal and regulatory function of taxes, principles and legal bases of realization of the state's fiscal policy, at the same time without separating it into an independent economic category. Often the criteria given to the studied category are not clear enough, which creates problems in determining its essence and economic nature.

The lack of sufficient theoretical and methodological basis is evidenced by the fact that still in international economic dictionaries there is no definition of tax security as an economic category, and in official regulations, in particular the concepts of national security instead of tax security uses the concept of national security in the tax sphere (USA, Russian Federation, Ukraine, Italy, Canada etc.) or legal security of taxation (France, Spain, Morocco), which is a significant drawback.

A review of scientific publications on the research problem showed that the existing definitions of the definition of "tax security of the state" show a divergence of views (Table 1), due to the fact that on the one hand it characterizes a certain state that protects the interests of taxpayers and entities, who are involved in the distribution of gross domestic product (GDP) through the tax mechanism, on the other - is a certain property of the system that can ensure the timeliness of the tax system to perform its functions and adequacy to respond to the changes of the state's tax policy under the influence of factors; on the third - the ability to resist risks and dangers, optimize, and under certain conditions, minimize their impact on all participants in tax security.

\section{Table 1. Morphological analysis of the study of the concept of ,tax security of the state“}

\begin{tabular}{|c|c|}
\hline Author, source & The concept meaning \\
\hline $\begin{array}{l}\text { I. Temoveeva, } \\
\text { 2011, p. } 24\end{array}$ & $\begin{array}{l}\text { Such status of the tax system, which provides a guarantee of protection of the state's tax interests, business } \\
\text { and society from internal and external threats. }\end{array}$ \\
\hline $\begin{array}{l}\text { Y. Tsimbalyuk, } \\
2013, \text { p. } 15\end{array}$ & $\begin{array}{l}\text { This is a status of the state's tax sphere, which is characterized by the protection of the entities } \\
\text { interests of tax relations, stability and economic independence of the tax system, which is } \\
\text { manifested in the stability of tax legislation; the ability of tax system to develop and improve, the } \\
\text { ability to timely identify and prevent potential threats in the field of taxation and the ability of the } \\
\text { tax system to fully implement all tax functions, both fiscal and regulatory and social, in order to } \\
\text { maximize the interests of the state and taxpayers. }\end{array}$ \\
\hline $\begin{array}{l}\text { A. Tsviliy- } \\
\text { Buklanova, 2011, } \\
\text { p.15 }\end{array}$ & $\begin{array}{l}\text { It is a subsystem of the state's national security, is a status of the tax system, which provides guaranteed } \\
\text { protection and harmonious development of the entire state's tax system, the ability of tax instruments to } \\
\text { protect national interests, maintain a society's socio-economic stability, and generate sufficient financial } \\
\text { resources for state and local management, successful confrontation with existing threats to the tax system. }\end{array}$ \\
\hline $\begin{array}{l}\text { V. Alyoshin, } \\
\text { V. Ovchinnikov } \\
\text { 2012, p. } 20-21\end{array}$ & $\begin{array}{l}\text { ent of the financial system as a whole } \\
\text { ter internal and external threats to fina }\end{array}$ \\
\hline $\begin{array}{l}\text { I. Lutsenko, } \\
2015, \text { p.160-161 }\end{array}$ & $\begin{array}{l}\text { This is a state of the taxation system that affects the providing of resc } \\
\text { the development of an independent, stable competitive national econ } \\
\text { protection of economic interests from external and internal threats in th }\end{array}$ \\
\hline $\begin{array}{l}\text { O. Fouquet, } \\
2013\end{array}$ & $\begin{array}{l}\text { Tax security is only tax version of legal security, defined by the rules of tax law, which must be sufficiently } \\
\text { predictable and understandable, ensuring their effective application in a fair manner, both by the } \\
\text { administration and taxpayers. }\end{array}$ \\
\hline $\begin{array}{l}\text { M. Bouvier, } \\
2016\end{array}$ & $\begin{array}{l}\text { It is a special state policy that combines three logics: political, economic and financial logic; is } \\
\text { crucial as a relationship between tax administrations and taxpayers; acts as a prominent factor in } \\
\text { the development of business and the economy as a whole; is a necessary condition for the growth } \\
\text { of tax revenues to the budget and the stability of state's finances; is one of the conditions for the } \\
\text { quality of social relations and well-being in society in the modern context and the function of future } \\
\text { events in the field of taxation. }\end{array}$ \\
\hline $\begin{array}{l}\text { D. Criclivaia, } \\
\text { I. Bruma, 2010, } \\
\text { p. } 116-118\end{array}$ & $\begin{array}{l}\text { It is a systematic method used by tax organizations in their activities, aimed at preventing damage } \\
\text { and minimizing risks to the budget after the loss of tax revenues due to fraudulent schemes, tax } \\
\text { evasion, etc. }\end{array}$ \\
\hline $\begin{array}{l}\text { Y. Ivanov, } \\
\text { Y. Berezhna, } \\
2010, \text { p. } 9\end{array}$ & $\begin{array}{l}\text { Tax security should be considered as an integrated subsystem of economic security, which affects } \\
\text { the financial security of all its components: innovation and technology, investment, energy, raw } \\
\text { materials, food, social, export, import and international integration security. }\end{array}$ \\
\hline
\end{tabular}




\begin{tabular}{|l|l|}
\hline $\begin{array}{l}\text { I. Chursina, } \\
2009, \text { p. } 6\end{array}$ & $\begin{array}{l}\text { Tax security (as a component of economic security) is a resource factor of the state (possibility of filling } \\
\text { the budget); instrument of influence on economic and social processes (follows from the regulatory } \\
\text { function of taxes); factor of feedback and dependence of the state on taxpayers. }\end{array}$ \\
\hline $\begin{array}{l}\text { M. Knyazeva, } \\
2017, \text { p. } 87\end{array}$ & $\begin{array}{l}\text { Tax security is a qualitative characteristic of the tax system, and this property should determine its } \\
\text { ability to withstand risks. }\end{array}$ \\
\hline $\begin{array}{l}\text { I. Borodushko, } \\
2010, \text { p.110 }\end{array}$ & $\begin{array}{l}\text { Tax security is determined by the integrity of such elements as the entities' activities of providing } \\
\text { tax security and a set of mechanisms and tools necessary to maintain the safe status of the state's } \\
\text { tax system. }\end{array}$ \\
\hline
\end{tabular}

Source: generalized on the basis of a study of the content of scientific publications.

Therefore, the problem of a unified approach to the interpretation of tax security has not yet been achieved. Systematization of existing scientific views has contributed to underline several scientifically sound approaches to understanding this category: level, functional, systematic, management and integrated approaches (Fig.2).

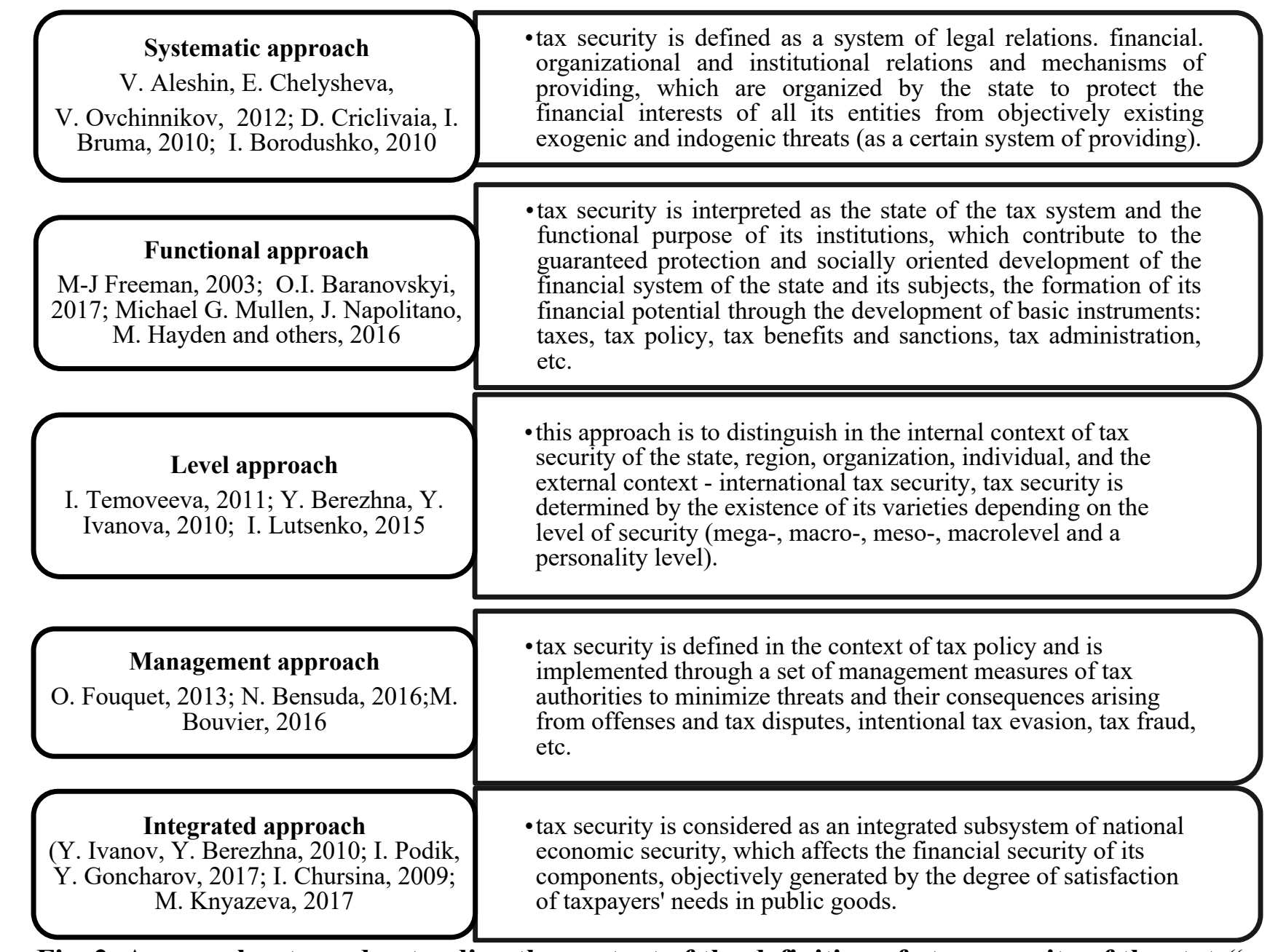

Fig. 2. Approaches to understanding the content of the definition of ,tax security of the state“

The separation of approaches allows to describe as fully as possible within the study the economic nature of the definition of "tax security", taking into account the impact of national and globalization processes, endogenic and exogenic factors on its formation. These methodological approaches are the basis for the formation of rational and practical models of tax security of the state, which are aimed at achieving both current goals and strategic goals of socio-economic development of the state through proper tax risk management and increasing the financial potential of the state. 
The functional approach characterizes the purpose and functions of the main components of tax security through the status assessment of taxation system, the effectiveness of tax system and tax policy (Freeman, 2003; Baranovskyi, 2017; Michael G. Mullen, J. Napolitano, M. Hayden and others, 2016). In our opinion, this approach deserves attention, but requires substantiation of the functions of tax security, qualitative and quantitative assessment of the taxation system status through the criteria for assessing the state's tax security on the national scales and in the international context.

The obtained generalizations contributed to the separation of the following functions of the state's tax security: fiscal-oriented (the ability to fill the budgets of different levels at the optimal level of taxation); social providing (the prospect of meeting the socio-economic needs of society under conditions of fair distribution of budget funds formed by tax revenues); regulating (a tool for regulating relations between the state and taxpayers); governing (factor of dependence and feedback between taxpayers and the state, regional authorities); stimulating (optimization of tax burden level, increase of business activity of economic entities and volumes of tax revenues); consolidating (characterizes the strengthening, unification, integration and legal regulation of countries' relations on taxation in the condition of globalization).

Representatives of the management approach mostly define tax security too narrowly - in the legal aspect (Bensouda, 2016), in particular defining it as a set of measures in the field of tax administration, or a certain direction of tax policy to regulate legal relations between taxpayers and a state, as a measures' result of claims minimization of tax authorities in case of occurrence or possibility of tax disputes (Chursina, 2009), or as a simple component of legal security in the field of taxation (Fouquet, 2013). Within this approach, it is important to create appropriate legal support that will help achieve a tax compromise for taxpayers, whose disputes with the tax authorities have already been sent to court or will be sent in the future (Baranovskyi, 2017, p. 12). However, no less important, for the formation of an appropriate level of the state's tax security and its entities, also other forms of providing exist, including organizational, informational, institutional and financial, are equally important.

Summarizing the opinion of the representatives of the management approach to the understanding of tax security, in our opinion, the studied category should be considered comprehensively in the context of legal, social and economic aspects of its formation. This approach necessitates the provision of an appropriate level of tax security by streamlining the tax policy of the state, regions and economic entities, taking into account the close relationship with the general financial, economic and social policy through their legal regulation (table 2).

Table 2. Characteristics of tax security in the context of areas of its formation (Vykliuk, Gresyk, 2013)

\begin{tabular}{|c|l|}
\hline $\begin{array}{c}\text { Areas } \\
\text { aspect }\end{array}$ & $\begin{array}{l}\text { Characteristic } \\
\text { In this aspect, tax security is characterized as a constant, but dynamically changing source of financial } \\
\text { resources of different levels budgets, the content of which depends on the degree and pace of economic } \\
\text { development, GDP growth, inflation level and tax burden degree of economic entities that involved in } \\
\text { public reproduction. In this regard, often in financial theory is considered the fiscal or economic efficiency } \\
\text { of taxes and the tax system, which determine the level of tax security providing of the state and its entities. }\end{array}$ \\
\hline $\begin{array}{c}\text { Social } \\
\text { aspect }\end{array}$ & $\begin{array}{l}\text { From the social point of view, tax security should be considered as protection of the balance of interests } \\
\text { of the state, business entities and population due to fair taxation and giving tax benefits, tax collection } \\
\text { and optimal redistribution of tax revenues (as a state budget resource) among all financial system entities, } \\
\text { forming a proper tax culture and discipline, which ensures the appropriate level of their tax security. The } \\
\text { most complete social orientation of tax security is manifested through the ratio of direct and indirect taxes. } \\
\text { The excess of direct taxes in the structure of all taxes indicates, first of all, the protection of the interests } \\
\text { of population's social groups. This allows to reduce the tax burden on consumers, and under optimal rates } \\
\text { and sizes of indirect taxes, activate production processes in the national economy. }\end{array}$ \\
\hline $\begin{array}{c}\text { Legal } \\
\text { aspect }\end{array}$ & $\begin{array}{l}\text { In this context, tax security should be seen as a process of regulating the tax sphere by creating conditions } \\
\text { for fair taxation of the entities of public reproduction and declaring these conditions in legislation. At the } \\
\text { same time, the regulated provisions are not only an idea, but a practical tool for implementing certain } \\
\text { state programs, which reduces the risks associated with intentional tax evasion, minimizes tax risks for } \\
\text { all taxpayers by practically creating tax regimes, taxation systems, transparent, clear and stable tax } \\
\text { legislation. }\end{array}$ \\
\hline
\end{tabular}




\section{Mariana Vykliuk, Rostislav Mikhailishin, Oleksandr Kundytskyj, Oksana Senyshyn, Natalia Prokopenko, Volodymyr Olikhovskyi

It is indisputable that the set of socio-political goals of any state is manifested through its economic impact on public relations of economic entities that have different social value and require appropriate tax security by forming different options of such relationships. Accordingly, there are the following models of tax security forming (Table 3): liberal, social democratic and authoritarian (undemocratic) (Timofeyeva, 2011, p.25-26). It should be noted that a choice of one or another model depends on the system of law, which valid in a country and the degree of rigidity or liberality of state participation in providing a control of tax security of all taxable entities.

Table 3. Characteristics of tax security models of states

\begin{tabular}{|c|c|c|}
\hline \multicolumn{3}{|c|}{ Variety of the state's tax security model: } \\
\hline Liberal model & Social-democratic model & $\begin{array}{c}\text { Authoritarian } \\
\text { (undemocratic) model }\end{array}$ \\
\hline $\begin{array}{c}\text { Great Britain, Australia, Canada, } \\
\text { USA, Sweden, Japan }\end{array}$ & $\begin{array}{c}\text { France, Poland, Germany, Italy, Spain, } \\
\text { Ukraine, Lithuania, Latvia }\end{array}$ & $\begin{array}{l}\text { Venezuela, China, } \\
\text { North Korea }\end{array}$ \\
\hline $\begin{array}{l}\text { It provides for the minimization of } \\
\text { state participation in the financing of } \\
\text { social programs, priority business } \\
\text { expansion, ensuring tax security of } \\
\text { business, the priority of economic } \\
\text { development policy over social } \\
\text { programs. Preference is given to } \\
\text { direct taxation (personal income tax, } \\
\text { corporate income tax) }\end{array}$ & $\begin{array}{l}\text { It provides for the proper level of tax } \\
\text { security of the state and society by } \\
\text { reducing social tensions between rich } \\
\text { and poor members of society through } \\
\text { high levels of taxation, real social } \\
\text { support, public funding of social } \\
\text { programs, while combining legal and } \\
\text { infrastructural methods of tax security. } \\
\text { Preference is given to indirect taxation } \\
\text { (VAT). }\end{array}$ & $\begin{array}{l}\text { Based on strict legal regulations } \\
\text { of taxable entities. Consists of } \\
\text { systematic control over } \\
\text { compliance with tax legislation; } \\
\text { involves the use of imperative } \\
\text { methods, maximization of taxes } \\
\text { through dictatorship to restore the } \\
\text { economic potential of the state } \\
\text { and overcome the crisis, the } \\
\text { predominance of state interests } \\
\text { over the interests of society }\end{array}$ \\
\hline
\end{tabular}

Principles of construction to the payment of taxes mechanism

Voluntary payment of taxes and compliance with tax legislation; the key principles of the organization of the tax system are systematization, flexibility and social orientation; focus on the implementation of public awareness and information-consulting activities; use the fiscal rescript system.
Fiscal planned nature of filling the state budget; high level of tax burden on the taxpayer; tight control

\section{Tax regulation system}

Unified system of regulation and control. All taxable entities comply with the general rules and regulations of national tax legislation; camera and documentary inspections

\section{Availability of specialized organizations and businesses that provide advice to individual taxpayers on} legitimate ways to reduce tax liabilities and keep tax records

There are special tax organizations (commercial and non-commercial), the purpose of which is to form partnerships to address many issues of taxation, advice on optimizing the activities of the taxpayer in terms of tax rate's speed, optimization of the object's taxation, use of tax regimes, ensuring the protection of the interests of taxpayers in terms of resolving disputes over the amount and size of taxation, etc.
There are no specialized government organizations that provide advice on taxation. The relationship cannot be described as a partnership aimed solely at maximum tax collection

\section{Tax authority that ensures the tax security of the state}

Internal Revenue Service of the Ministry of Finance (USA), Tax

Committee of the Ministry of

Finance (Canada), Treasury (UK), Tax Agency (Sweden)
Main Tax Department of the Ministry of

Economy, Finance and Budget (France), Federal Office of Finance (Germany),

Tax Service under the Ministry of

Finance (Italy), Tax Chamber at the

Ministry of Finance (Poland), State Tax

Service (Ukraine), State Revenue Service (Lithuania)

Source: formed by the author on the basis of publications (Timofeyeva, 2011; Podik, Goncharov, 2017; Bensouda, 2016; Vykliuk, Gresyk, 2013).

General State Tax Administration

(China), State Tax Administration (North Korea, Venezuela) 
Representatives of the integrated approach (Ivanov, Berezhna, 2010; I. Podik, Y. Goncharov, 2017; I. Chursina, 2009; Knyazeva, 2017) tax security of the state is considered as a component of national, economic or financial security of the state through the implementation of the fiscal and regulatory function of taxes and the formation of financial security of the state. According to them, tax security has an impact on all components of national security (innovation and technology, investment, energy, raw materials, food, social, export, import and international integration security). Proponents of this approach argue that it is fiscal interests that play a key role in the system of national interests and emphasize the regulatory aspect of taxes as the main tool for ensuring tax security and stimulating business activity of economic entities.

According to the adherents of the integrated approach, the implementation of directions for democratic market transformations of the vast majority of countries largely depends on the created conditions for the effective functioning of the budget and tax spheres. Therefore, tax security has a significant impact on the effectiveness of budget policy, because through the stimulation of business activity determines the level and structure of tax revenues and, accordingly, considers it solely as an optimal mechanism for filling the budgets of budgets at different levels. Therefore, tax security has a significant impact on the effectiveness of budget policy, because through the stimulation of business activity determines the level and structure of tax revenues and, accordingly, considers it solely as an optimal mechanism for filling the budgets at different levels.

However, in our opinion, it is inexpedient to define the tax security of the state exclusively as a source of financial support of the state and a source of filling the budget, because: first, taxes are not the exclusive source of state budget revenues, although the main one; secondly, to interpret tax security only through the prism of taxes as a source of the budget is impractical, because the studied category is much broader in its content, which is as follows: tax security is inextricably linked with the process of tax management; determined by the effectiveness of tax policy, the functioning quality of the tax system and tax administration, the tax competitiveness of the state in the world community; third, the state's tax security should be the basis for the progressive development not only of the financial system of the state, but also of taxpayers (households, businesses, sectors of the national economy, regions and state as a subject of international relations). This requires an increase in the number of entities that are taxable and need to meet financial interests within the existing financial potential of the state.

The systematic approach to understanding tax security, in our opinion, is the most reasonable approach among all existing approaches, as it allows to study the economic nature and essence of tax security by studying the characteristics of the system and the elements in their relationship. It should be noted that the systemic approach combines several approaches at the same time, because most scholars representing other approaches, in their scientific papers propose to define the tax security of the state as a system of relations (legal, organizational, financial and institutional) operating in the field of taxation or a system of measures and mechanisms organized by the state to protect the financial interests of all its entities from objectively existing external and internal threats [31, p.22]. Noteworthy are the scientific studies of the systematic study of tax security in the work of V. Aleshin, V. Ovchinnikov, Y. Chelysheva (2012), I. Timofeeva (2011) and some aspects of the systematic approach D. Criclivaia and I. Bruma (2010), M. Bouvier (2016), M. Knyazeva, E. Davydova (2017).

For example, the representative of the management approach, scientist and public official Michel Bouvier ("Tax security: big problems today", 2016), presents his own conceptual approach to understanding the tax security, where the author emphasizes that tax security is a special state policy, which combines three logics: political logic (operates in the legal field and is a kind of political project, focused on the democratic traditions of tax collection, the use of special secure forms of administration taxes and ways of organizing tax law, requires constantly change and improve the tax rules); economic logic (this component is crucial because economic imperatives relate to the dynamics of consumption and level of business investment, their competitiveness; it is especially important to ensure tax security in a globalized environment, when the level of tax insecurity 
increases for both the state and taxpayers); financial logic (manifested in tax instability, which arises as a result of non-fulfillment of their tax obligations by the taxpayer and may lead to a decrease in budget revenues) [24].

Noteworthy is the systematic approach to the consideration of tax security as a systematic method of avoiding and minimizing tax risks, optimizing the tax burden on taxpayers, presented in the work of scholars D. Criclivaia and I. Bruma (2010). The authors note that the activities of all organizations that provide fiscal security are aimed only at preventing damage to the budget after the loss of tax revenues, while ignoring the interests of taxpayers. Accordingly, fraudulent schemes are already envisaged, as a result of which the state may suffer significant losses in terms of tax revenues, and as a result of logical thinking, we get a chain of fiscal uncertainty and tax evasion. In this regard, the authors proposed a special method that would open the heads of the national fiscal apparatus a complete picture of the situation, confirming the figures of the recommendations of specialists responsible for fiscal security in the institution (Criclivaia and I. Bruma, 2010).

Some aspects of the system approach are applied in the collective works of the authors V. Aleshin, V. Ovchinnikov, E. Chelyshev (2013), where the system paradigm of the state's tax security and its regions is highlighted. According to the authors, a systematic approach in tax security research should predict: determining the quantitative and qualitative characteristics of the state's tax system in comparison with other systems (eg, systems of developed foreign countries) to achieve financial security goals; identification of existing shortcomings inherent in the tax system, which led the economy to crisis, as well as inhibit innovative development; determining the degree and effectiveness of the interaction and interdependence of the evolution of the tax system and tax administration; clarification and coordination of economic interests and preferences of the subjects of tax relations and the system as a whole; study the dialectic of the elements' development of the system: from private to public, and vice versa (Aleshin..., 2013, p.21-22). In our opinion, the scientist I. Timofeeva substantiates and allocates tax security in a separate complex strategic direction of economic security of the state and represents it as the system phenomenon on the basis of the analysis of methods of its maintenance. The author studies tax security from the standpoint not only of the effective functioning of the tax system, but also ensuring the safe existence of all its elements, and the subjective composition of tax security is represented by the interests of business, society, state, which correlates with national security as a part of the whole, as a subsystem of national economic security. The work presents the concept of tax security, which should consolidate the tax interests of both state representatives and representatives of business, public organizations, as well as each individual citizen; the author's concept of tax security is presented, which includes the formulated goals, tasks set to provide functions, multifactor classification of tax risks, as well as the structure and specified system characteristics of its most important (Timofeyeva, 2011, p.24-39).

The level approach (Timofeyeva, 2011; Bensouda,_2016; Berezhna, Ivanova, 2010; Lutsenko, 2015; Mironova), 2016, which considers the tax security at different levels of formation, is gaining considerable popularity among researchers today. In particular, in the domestic context, the tax security of the state (macrolevel), region (mesolevel), organization (microlevel), individual (individual level), and from the standpoint of external providing - international tax security (megalevel), which is formed under the influence of globalization and integration processes of the state. The last one forms the external frameworks of the state's activity and behavior, regarding the formation of the state's model of tax security.

The definition of a multilevel system of tax security is conditioned by the fact that the interests of not only the state and society, but also all citizens, groups, enterprises and organizations, the international business community are connected with the distribution of GDP and taxation. As a result of such processes, the financial potential of the state is formed, which allows it to maintain normal living conditions of society, state, population and business. In the context of constant globalization, special consideration is given to the state's tax security at the international level, which is implemented through international economic cooperation in the field of taxation between countries 
to solve the tax base's eroding, illegal transfer of profits and interpenetration of capital from one country to another. Therefore, tax security has become an international problem today, and its interpretation and stability go beyond one country. With this in mind, ensuring the state's tax security should be based on the following principles: equal taxes on an equally big amount of taxation (income, profit, property, etc.); legislative consolidation and establishment of taxes taking into account economic expediency and national interests; exclusion, if possible, of double taxation through the cooperation of states within the framework of international tax legislation; stability and longevity of tax rates (Bensouda, 2016; Bouvier, 2016). International institutions such as the Organization for Economic Cooperation and Development (OECD) and the Group of Twenty (G20) and the United Nations are addressing these issues in the relevant legal field (Table 4). Their activities are focused on the formation of legal mechanisms to ensure the tax security of states and international entities of the tax process. The purpose of these organizations is to form joint agreements between the countries to prevent double taxation of one object in two countries and to form a plan to combat the tax base's eroding and the withdrawal of profits from taxation by the participating countries (Base Erosion and Profit Shifting, BEPS, Basic World Tax Code). According to research by the Organization for Economic Cooperation and Development (OECD) tax evasion by the tax base's eroding and transfer of profits from one country to another is about from $\$ 100$ billion to $\$ 240$ billion annually (4-10\% of total income tax) (About BEPS..., 2017).

Table 4. International principles of providing the countries' tax security

\begin{tabular}{|c|c|c|}
\hline \multicolumn{3}{|r|}{ Directions } \\
\hline \multicolumn{3}{|r|}{ Organization of economic cooperation and development (OECD) } \\
\hline $\begin{array}{l}\text { Convention } \\
\text { on double } \\
\text { taxation of } \\
\text { income and } \\
\text { capital } \\
\text { (1963, as } \\
\text { amended, } \\
\text { in } 1977 \text {, } \\
1992)\end{array}$ & 4) & $\begin{array}{l}\text { formation of a national model of acceptance and avoidance of double taxation, which includes the } \\
\text { following elements: types of taxes regulated by agreement between countries; a list of entities } \\
\text { covered by the consent, including for entities permanently located in one of the countries of the } \\
\text { agreement; ways to avoid double taxation (property, copyright, international transportation, fees and } \\
\text { contributions to the social insurance system); determination of tax conditions (establishment of } \\
\text { restrictions); determining the method of taxation of such entities, including income in the form of } \\
\text { commercial income, scholarships, social benefits, pensions, etc.; the procedure for fulfilling the } \\
\text { agreements of the parties; } \\
\text { non-discrimination of taxpayers, including non-residents; } \\
\text { avoidance of illegal mechanisms of money laundering and tax evasion, in particular by international } \\
\text { business participants by including additional provisions on information exchange and mutual } \\
\text { assistance in identifying threats to the state's tax security through illegal actions, agreements with } \\
\text { offshore zones; agreements «treaty shopping» to minimize the tax burden; transfer pricing; } \\
\text { operation of captive insurance companies (those that insure the risks of their depositors) in free tax } \\
\text { zones (Bermuda); } \\
\text { standardization and unification of national tax legislation to international requirements of } \\
\text { administrative procedures for taxation of residents and non-residents; } \\
\text { harmonization of the state's tax policy and tax system, etc. }\end{array}$ \\
\hline \multicolumn{3}{|r|}{ «Group of twenty» (G20) } \\
\hline & 1) & \\
\hline $\begin{array}{l}\text { Erosion } \\
\text { and Profit } \\
\text { Shifting, }\end{array}$ & 2) & $\begin{array}{l}\text { presents a set of tax planning strategies that allow bussnesses to declare their profits for taxation in } \\
\text { jurisdictions, where they have not operated and economic activity has caused the withdrawal of } \\
\text { these profits and income tax rates are relatively low (or zero); }\end{array}$ \\
\hline $\begin{array}{l}\text { BEPS, } \\
1998\end{array}$ & 3) & $\begin{array}{l}15 \text { general measures have been formed, which predict the introduction of a number of instruments } \\
\text { that allow the project participating countries to implement the fight against illegal transfer of profits } \\
\text { and tax evasion. In particular, these measures may differ in different countries. It depends on the } \\
\text { needs of national legislation and agreements between the countries parties to the treaty. }\end{array}$ \\
\hline \multicolumn{3}{|r|}{ United Nations (UN) } \\
\hline $\begin{array}{c}\text { Basic } \\
\text { World Tax }\end{array}$ & 1) & $\begin{array}{l}\text { grounds of effective international tax regulation in various conditions } \\
\text { oning under the influence of globalization processes; }\end{array}$ \\
\hline Code, 1996 & 2) & $\begin{array}{l}\text { consultations and recommendations for countries with economies in transition on the } \\
\text { implementation of tax policy, implementation of tax legislation, its implementation to international } \\
\text { standards, reforming the countries' tax system. }\end{array}$ \\
\hline
\end{tabular}


It is worth noting that tax security can not only maintain the necessary balance in the financial system and stimulate the tax potential's growth, but also have the opposite effect under conditions of excessive tax burden and pressure on business structures - reducing the tax potential. As a result, tax risks are formed, which negatively affect the financial security of all levels and carry at the same time social, structural, regional (territorial), in the business sector and criminal threats to both the state's national and financial security, in particular.

The obtained generalizations allowed to single out the main factors of tax threats (negative economic and social consequences for the state's tax and budget systems) that cause tax evasion: a large number of taxes that negatively affect the quantity, structure and quality of tax revenues; the existing tax legislation and the procedure for collecting taxes and fees takes into account only the state's interests; ambiguous interpretation of tax legislation; tax regulation is unstable, has a shortterm character and predicts to eliminate the budget deficit; ignoring the consequences of the tax burden's distribution between the taxable parties when introducing new taxes or changing tax rates; inefficiency of the current tax system (the presence of numerous unjustified tax benefits, low level of tax collection, violation of the principle of proportionality: raising rates after the threshold level for honest taxpayers leads to a reduction in tax revenues); fictitious reduction of the tax base by businesses and non-inclusion of certain revenues in the object of taxation (received payments for credit resources, interest on loans, funds from the sale of foreign currency, etc.); withdrawal of financial capital from the country and concealment of significant amounts of tax revenues by business entities; lack of tax culture and discipline among the participants in the tax process; lack of international cooperation on taxation of international corporations and other businesses, or activities that go beyond the state, implemented by non-residents in a particular country's territory, and so on.

Ability to correctly identify and assess threats to tax security, able to minimize the likelihood of risk and increase the effectiveness of tax security. Thus, the state as a subject of the tax system to ensure effective tax security constantly regulates and stimulates the economy by reducing and optimizing the level of taxation of business entities. The last ones bear tax liability for violating tax laws, which determines their own level of tax security. Therefore, the dynamic development of the economy and the rational management of budgetary resources should be focused on the formation of such tax security that should satisfy the interests of economic agents at a sufficient or necessary level. This approach allows to determine the level of tax security not only through quantitative criteria, but also to give a qualitative description to the state of its stability and ability to effectively develop and counter existing threats.

However, in our opinion, substantiation of the content and nature of tax security only at these levels allows only to get an idea of its formation, but does not allow to create a comprehensive view of it as a phenomenon, characterized by dynamism, variability, qualitative and quantitative justification, systemic nature. Accordingly, the study of this multifaceted and complex concept must be carried out using a systematic approach, which allows through the study of specific characteristics of the structure to identify its economic nature and essence (Fig.3).

Synthesizing the conducted researches, it should be noted that the state's tax security should be understood, as the tax system's state, which determines the harmonization process of taxation and tax collection, on condition of effective management of risks and threats arising in a tax sphere, by taking the necessary measures, on the part of the executive bodies to meet interests of the state, society and taxpayers (business entities, organizations, population). 


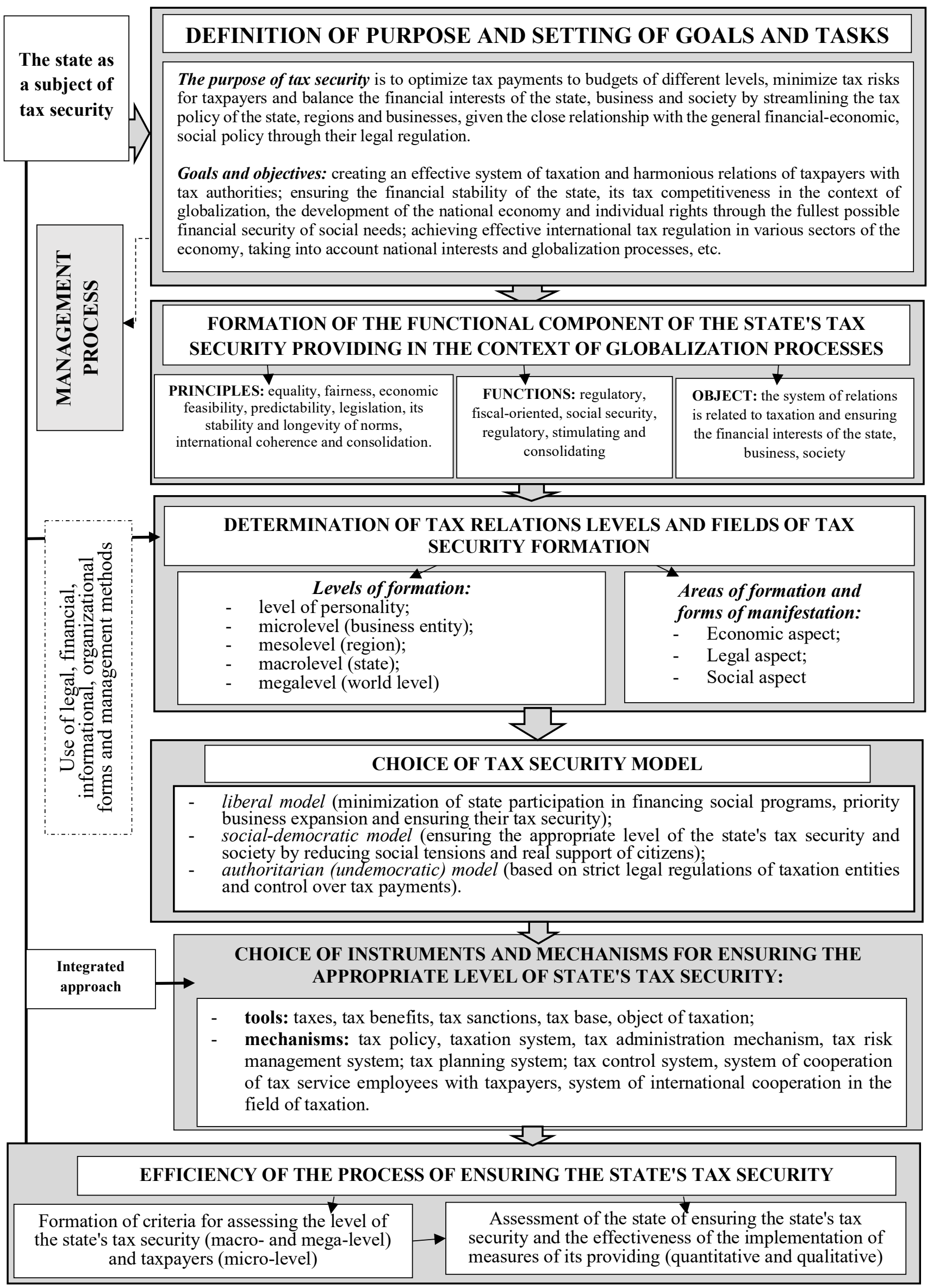

Fig. 3. The conceptual basis of the state's tax security model 


\section{Conclusion}

In scientific research the theoretical generalization is made and the conceptual basis of ensuring the state's tax security is presented. The made generalizations allowed to get the following results:

- the existing scientific approaches to views on the content and nature of the definition of "state's tax security" are systematized, namely: systematic approach, functional approach, hierarchical approach, level approach, management approach;

- noted that the most rational in the modern globalization of the state's functioning is the use of a systematic approach to the state's tax security providing, which allows to comprehensively characterize the forms and spheres of tax security manifestation, features of the state's tax security model formation, taking into account levels of its providing (mega-, macro-, meso-, micro-level and personality level);

- done the characteristic of existing models of the states' tax security (liberal, social-democratic and authoritarian/undemocratic models), which reveal the peculiarities of ensuring tax security of a certain country taking into account national peculiarities and interrelation with globalization processes, which accompany the tax sphere;

- presented the author's understanding of the definition of "state's tax security" as a certain status of the tax system, which determines the harmonization of taxation and tax collection under the effective management of risks and threats, arising in the tax sphere, by taking necessary measures by executive bodies to meet state interests, society and taxpayers (businesses, organizations, population).

- formed the conceptual basis of the state's tax security model on the basis of the systematic approach, representing the system which includes set of interconnected structural elements, namely: the purpose of the state's tax safety providing, goals and objectives, methods and forms of management (organizational, financial, legal, informational); the functional component of providing the state's tax security in the context of globalization processes (principles, functions, object); tax relations levels and tax security formation sphere; choice of the tax security model for the state; a comprehensive approach to the use of tools and mechanisms to ensure the appropriate level of the state's tax security and effectiveness of measures implementation to ensure its (quantitative and qualitative assessment).

- the presented scientific provisions will contribute to the improvement and development of scientific thought on the understanding of the state's tax security as an important component of national security and formation of its conceptual foundations.

\section{References}

About BEPS. - http://www.oecd.org/ctp/beps-about.htm [2020 02 01].

Aleshin, V. A., Ovchinnikov, V. N., Chelisheva, E. A. (2012). System Paradigm ensure fiscal security of Russia and its regions. // Terra economicus. Vol. 1. No. 1.: 20-26.

Baranovskyi, O.I. (2017). Tax security: substance. // Collection of scientific works of the University of the State Fiscal Service of Ukraine. No. 1: 7-24. - http://nbuv.gov.ua/UJRN/znpnudps_2017_1_3.

Basic World Tax Code (Russian language version, 1996)

http://www.taxhistory.org/www/bwtc.nsf/PDFs/98rus96a.pdf/\$file/98rus96a.pdf [2020 02 03].

Bensouda, N. (2016). The real challenges of tax security. Grandstand. No. 4731 (03/17/2016). https://www.leconomiste.com/article/995263-les-vrais-enjeux-de-la-s\%C3\%A9curit\%C3\%A9-fiscale1 [2020 04 02].

Bouvier, M. (2016). Tax security: today's big issues. https://www.tgr.gov.ma/wps/wcm/connect/c488615f-e3d8-462a-94d4-b0ce3f9a46cc/Bouvier++$+\mathrm{s} \% \mathrm{C} 3 \% \mathrm{~A} 9$ curit $\% \mathrm{C} 3 \% \mathrm{~A} 9+$ fiscale.pdf?MOD=AJPERES\&ContentCache=NONE [2020 04 02].

Borodushko, I.V. (2010). Tax security: concepts and essence. // Vesnik of the Sank-Petersburg University of the Ministry of Internal Affairs of Russia. No. 2 (46).: 108-112. 
Criclivaia, D., Bruma, I. (2010). Fiscal security: identifying sources of threats. // Study at the State University of Moldova. No. 7 (37): 116-120. - https://www.researchgate.net/publication/273457238.

Chursina, I. (2009). The influence of the shadow economy on the tax component of economic security. // The synopsis of the thesis of the candidate of legal scienses. - Moscow, p. 24.

Ivanov, Yu., Berezhna, Yu. (2010). Tax security: essence and conditions of provision. // Development economics. No. 2 (54): 9-11.

Freeman, M. J. (2003). States' Fiscal Crises: A National Security Issue. // Mary Jane Freeman. Vol. 30. No. 3 (21). - https://larouchepub.com/eiw/public/2003/eirv30n11-20030321/eirv30n11-20030321_007states_fiscal_crises_a national.pdf.

Fouquet, O. (2016). Special feature: tax security: plural points of view. // Introductory report. - file: /// C: /Users/Admin/Downloads/286-639-1-SM.pdf [2020 04 02].

Knyazev, M., Davydova, E. (2017). Theoretical and methodological approaches to the formation of the tax security system in Russia. // Proceedings of the FEFU. Economics and Management. No. 4.: 83-88.

Lutsenko, I.S. (2015). Methodical approach to assessing the level of tax security of the state. // Scientific Bulletin of Kherson State University. Vol. 12 (2).: 159-163.

Makutenas V., Krikstonaitiene D. (2017). Modeling of tax optimization opportunities in business enterprises. Management Theory and Studies for Rural Business and Infrastructure Development. 2017. Vol. 39. No. 3: 303-314. - http://DOI:10.15544/mts.2017.22.

Mironova, O.A. (2016). The tax security: the development of theory, methodology, practice. // The innovative development of economics. No. 3 (33).: 90-97.

Mullen, M. G., Napolitano, J., Hayden, M. and others (2016). Strength at home and abroad. Ensuring America's fiscal and national security a new statement from the Coalition for Fiscal and National Security. https://www.researchgate.net/publication/273457238 [2020 03 01].

Nazarova K., Hordopolov V., Kopotiienko T., Miniailo V., Koval V., Diachenko Y. (2019). Audit in the State Economy Security System. Management Theory and Studies for Rural Business and Infrastructure Development. Vol. 41. No. 3.: 419-430. - http://DOI: https://doi.org/10.15544/mts.2019.

Podik, I.I., Goncharov, Y.V. (2017). Tax component of economic security of Ukraine. - Kyiv: Interservice. $210 \mathrm{p}$.

Rossing, C. (2013). Tax strategy control: the case of transfer pricing tax risk management // Management Accounting Research. Vol. 24 (2): 175-194. - https://doi.org/10.1016/j.mar.2013.04.008.

Timofeyeva, I.Y. (2011). The tax security of the state, business and society: the conception and the methodology. // The synopsis of the thesis of the Dr. of Economics. - Moscow. 53 p.

Tsimbalyuk, I.O. (2013). Tax security in the system of financial security of the state. - Donetsk: SHEE "DonNT". Vol. 2.: 13-23.

Tsvilliy-Buklanova, A.A. (2011). The tax control in the system of the tax security of the state. // The synopsis of the thesis of the candidate of legal scienses. - Tchelyabinsk. $32 \mathrm{p}$.

Vykliuk, M.I.,, Gresik, V.V. (2013). Tax security: the dualism of the economic nature of the interpretation of the content of the main characteristics. // Innovative economy. No. 5: 242-246. file://C:/Users/Admin/Downloads/inek_2013_5_62\%20(1).pdf.

Wunder, H. (2009). Tax risk management and the multinational enterprise. // Journal of International Accounting, Auditing and Taxation. Vol. 18(1): 14-28. - https://doi: 10.1016/j.intaccaudtax.2008.12.003.

Zachosova, N. (2019). Financial Security: Problems of Operational and Strategic Management, Risks and Peculiarities of Public Administration. - Przeworsk: WSSG. 114 p. 